\title{
Antídoto e método: práticas de investigação artística em contexto coreográfico
}

\author{
SÍLVIA PINTO COELHO
}

Since 1999 I've been following João Fiadeiro's work with some attention. Sharing his processes of research with several colleagues, collaborators, artists, researchers, Fiadeiro has been able to produce myriads of questions under the umbrella of Real Time Composition (CTR). As I could explore some of these questions in workshops with Fiadeiro and his collaborators (first as a dance student, and later as an artist and researcher, 1999-2018), I ended up using them and exploring them further in my PhD dissertation Body, Image, and Choreographic Thinking (2016). A great portion of the present paper was written between 2012 and 2015 as part of this larger research project. ' Several research practices - such as Fiadeiro's CTR, Lisa Nelson's Tuning Scores, Mark Tompkins' Real Time Composition; Modus Operandi AND, or the Guest-Host (G.HOST) game practice, organized by Eugénio and Fiadeiro, among many - present ways to articulate strategies in order to create new meanings and to think with and about ways of acting-thinking. This paper tries to enhance the capacity that some of these practices have in themselves, and in the speech they produce, to generate the possibility of an antidote for each proposition (i.e. the possibility to escape dogmatic tendencies that methods in general reveal).

COMPOSIC̣ÃO EM TEMPO REAL / RE.AL / JOÃO FIADEIRO / AND_LAB / FERNANDA EUGÉNIO

INTRODUÇÃO

Acompanho o trabalho do coreógrafo João Fiadeiro com alguma atenção desde 1999. A convivência com a sua investigação e com dezenas de colegas, colaboradores, artistas, investigadores (nos quais me incluo)

1 From 2011 to 2014, João Fiadeiro and Fernanda Eugénio were collaborating in an intensive research project, the AND_Lab, that aimed to involve several researchers around a series of topics considering the emergence of community and composition (how to live together and how to arrive at compositions that emerge from a relation made of previous relations, instead of having preconceived ideas). In 2015 their research split again, the AND_Lab is being explored in various other perspectives with Fernanda Eugénio, myself and several researchers; João Fiadeiro's research went further with distinct influences and artists, and is called again CTR (Real Time Composition). 
produziu algumas das questões que desenvolvi na tese de doutoramento com o título Corpo, imagem e pensamento coreográfico, da pesquisa coreográfica contemporânea enquanto discurso: os exemplos de Lisa Nelson, Mark Tompkins, Olga Mesa e João Fiadeiro (2016). Uma grande parte deste artigo foi escrita em 2015 e integra uma investigação alargada, da qual destaco o período entre 2011 e 2013, quando acompanhei mais intensamente e de perto a formulação do Modo Operativo $A N D^{2}$, com Fernanda Eugénio e João Fiadeiro $^{3}$, deixando que o discurso produzido então influenciasse a articulação de vários temas. Falo de um discurso que subjaz às distintas práticas que pude experimentar ao longo de anos de estudo na área da coreografia. A prática da Composição em Tempo Real de João Fiadeiro, ou a de Cláudia Dias; a prática de Tuning Scores de Lisa Nelson; a prática de Real Time Composition de Mark Tompkins; a prática da improvisação Viva o Momento de Peter Michael Dietz; a prática do Modo Operativo AND, ou a prática do jogo Guest-Host (G.HOST) de Fernanda Eugénio e de João Fiadeiro, entre muitas, constituem estratégias de articulação, de criação de sentidos e de flexibilização de modos de pensar-agir que integrei «à minha maneira».5 Este artigo pretende evidenciar o modo como algumas destas práticas artísticas comportam em si, ou no discurso que produzem, um «antídoto», isto é, a possibilidade de não se cristalizarem em dogmas. ${ }^{6}$

2 «O Modo Operativo AND (MO_AND) é um sistema de improvisação e com-posição-com que oferece um conjunto de instrumentos para o estudo praticado das políticas da convivência e das capacidades de auto-observação em acto e de tomada de decisão situada. [...] o jogo AND permite frequentar a atenção ao comum, a disponibilidade para o imprevisto e o prazer da comunidade, articulando-se como convite com uma investigação experiencial dos funcionamentos e (des)dobramentos do Acontecimento - seja no acompanhamento da sucessão espiralada das suas emergências e esgotamentos, seja através do manejo directo da sua propagação em regras imanentes e sempre provisórias» (Eugénio/Salgado, 2018).

3 Neste mesmo período, tive acesso a vários tipos de documentos do arquivo da RE.AL e de João Fiadeiro. Do material por catalogar, mas suficientemente organizado, destaco alguns textos inéditos, recortes de jornais, fotografias e vídeos de várias épocas ligados a oficinas e a peças de João Fiadeiro.

4 Ao longo do tempo, as práticas dos dois coreógrafos foram ganhando características e focos distintos.

5 Em torno do trabalho e do pensamento de João Fiadeiro, a tentativa de ser absolutamente rigorosa na atribuição de autoria às ideias, expressões, abordagens e modos operativos talvez seja desnecessária e demagógica. No caldeirão das influências e das confluências, cabem muitas pessoas. O que eu penso que ele pensa que eu penso (Fiadeiro, 1992), o que ela pensa, o outro disse, alguém leu, citou, ou escreveu, se apropriou de... e agora aqui fica mais um artigo para actualizar um fluxo que há-de vir a ser actualizado mais tarde por outra corrente, outra posição posta em contraponto a esta-outra com-posição.

6 Independentemente de observarmos esta hipótese, consoante os modos de transmissão e as interpretações feitas das hipóteses lançadas, enquanto convite por vários autores, mais tarde ou mais cedo, há-de haver sempre alguém que usa «um método» como «a solução». 
Mes solos sont comme des laboratoires photographiques où je révélerais ce négatif de moi-même...

FIADEIRO/GUÉNIOT (2002)

O que eu sou não fui sozinho ${ }^{7} \mathrm{diz}$, por vezes, João Fiadeiro. É um facto, e é uma peça, mas também um marcador temporal e um ritornello existencial. Algo que escolhemos não esquecer. Algo que escolhemos repetir porque esquecemos demasiadas outras coisas que nos importam. Sob o signo da repetição com diferença, da actualização como memória do futuro, há que praticar o jogo de actualizar e de esquecer, de dar visibilidade e de escolher não o fazer. Ou, então, pelo contrário fazer um Retrato da memória enquanto peso morto (Fiadeiro, 1990). ${ }^{8}$ No jogo de palavras deste texto, muito do que escolhemos dizer encontramos depois escrito, de outra forma, num texto de Fiadeiro, num texto de André Lepecki, ou num de José Gil, ou de Fernanda Eugénio, de Paula Caspão, ou de... Ritornamos: «O que eu sou não fui sozinho», não somos sozinhos. Como escolher o recorte deste artigo para poder continuar a falar? «No fim tudo parecerá ter decorrido como parecia estar previsto» (Fiadeiro/Guéniot, 2002, tradução da autora). Até lá, gaguejamos.

É nesta zona desconhecida intermediária, nestas entrelinhas da estrutura que aquilo que normalmente se define como erro, ou passo em falso, se torna no preciso encontro com o «real», ou com qualquer coisa que, nem eu nem o espectador sabe que forma ou significado terá... Qualquer coisa que virá extrair a sua matéria, a sua razão de ser/estar em mim e falará de mim, apesar de mim. Qualquer coisa que vai revelar aquilo a que chamo o «negativo de mim próprio». (Fiadeiro/Guéniot apud Coelho, 2016: 197)

Se gaguejamos, ou «se tropeçamos, o espectador pensará que estava “escrito" assim [na encenação, na estrutura, nas tarefas a cumprir...]» (ibidem). De facto, agora enquanto eu escrevo ${ }^{9}$, o texto que ficará inscrito

7 O que eu sou não fui sozinho, peça de 2000, RE.AL/João Fiadeiro.

8 A primeira composição da Companhia RE.AL (REsposta ALternativa) terá nascido em 1990, com a peça Retrato da memória enquanto peso morto e com os colaboradores Nuno Bizarro, Ângela Guerreiro, Sílvia Real, Luciana Fina, etc. (Coelho, 2016: 196).

9 Tal como acontece na tese, a proximidade com as práticas que foram objecto de estudo leva-me a uma escrita performativa que justifica o uso da primeira pessoa, criando complexidade e confusão voluntárias entre um «eu» que escreve e os «eus» que cita. 
pode ser recomposto neste suporte. O leitor, por sua vez, nunca irá saber se se optou por esperar por o texto acontecer em sintonia com as estratégias da CTR de Fiadeiro - a não ser que o denunciemos; o texto, mesmo que «composto em tempo real», já está escrito. Talvez faça uma grande diferença este «estar escrito», já foi, e foi recomposto depois, claro! É diferente o quadro de apresentação, não estamos nem «ao vivo», nem em «tempo real», nem temos público no momento da escrita, mas ensaiamos também um método de improvisação.

Ao querer reproduzir esta realidade, privo-a do presente que a fez nascer, aquilo que dou a ver ao espectador [leitor] não é senão uma retransmissão em diferido, uma cópia mais ou menos fiel, mais ou menos conseguida, dos momentos [...] que se seguiram à nascença dessa coisa única, real, verdadeira... [...].

Ora, posso captar esta frase, nascida na improvisação, com um microfone e simultaneamente fixá-la num suporte que me permitirá voltar a escutá-la quase da mesma maneira. Eu sei que quem quer que vá ouvir este registo estará directamente na presença da parte audível deste fragmento de real que surgiu. 0 «problema» que a dança coloca é que não posso fixar esse momento num suporte mecânico, o suporte de que disponho está vivo. É uma pessoa e não um disco, ou uma película. Portanto, a credibilidade de um tal momento não existe senão através da colocação do espectador em presença da manifestação, da representação, da emergência do «real» que o intérprete vive... (Fiadeiro/Guéniot apud Coelho, 2016: 198)

\section{COMPOSIÇÃO EM TEMPO REAL}

Então, podemos dizer que «no fim [...] tudo aconteceu» ${ }^{10}$ assim: Composição em Tempo Real foi o nome que João Fiadeiro encontrou para a estratégia que tem vindo a trabalhar desde aproximadamente 1995. «Façam o vosso próprio método» terá dito Trisha Brown, durante uma conversa num workshop em que Fiadeiro participou em Nova Iorque (Jacob's Pillow Dance Festival, 1987). «E eu fiz», diz Fiadeiro gracejando,

10 «No fim, onde tudo aconteceu» (Fiadeiro, 2002) é um dos muitos textos inéditos, tentativas progressivas de descrever e de contar a história do seu método de Composição em Tempo Real. «No fim, "onde tudo aconteceu", sinto que não fui eu a fazer a peça, mas que foi ela a fazer-me a mim. Como se não tivesse tido escolha, como se não fosse eu que estivesse ali...» (Fiadeiro apud Coelho, 2016: 198). 
num workshop de CTR aplicado à criação dramatúrgica, em Agosto de 2014. A CTR poderá ser também um fruto desse repto de Trisha Brown. ${ }^{11}$

O meu primeiro projecto a solo - Solos - aconteceu em 1992 com o compositor-improvisador Miguel Azguime. É a ele que devo o meu primeiro contacto com a música contemporânea e com a música improvisada (mais tarde continuado com compositores como Nuno Rebelo e Vítor Rua), encontro que se revelou fundamental para o desenvolvimento do meu trabalho. Para este espectáculo encontrávamo-nos sempre no próprio dia de apresentação - resultado de uma mais que evidente influência da relação Cage-Cunningham - e a única marcação que tínhamos era um pequeno preâmbulo musical, onde, no seu final, eu me lançava ao ar, o mais alto que podia e, sem aplicar qualquer técnica de amortecimento da queda, deixava o meu corpo inerte embater contra o chão. A intenção era criar um novo ponto de partida, um zero a partir de onde tudo fosse possível. Essa experiência, a de me colocar num espaço em aberto, em potência, a viver a sensação de que tudo está por acontecer, foi fundadora no estabelecimento dos actuais contornos da metodologia de Composição em Tempo Real. (Fiadeiro, 2002 apud Coelho, 2016: 198)

Nestes solos, além das noções de casualidade e de imprevisibilidade, Fiadeiro terá introduzido também as noções de responsabilidade e de estrutura com o intuito de trabalhar a partir de uma ideia de «dramaturgia», que passaria a funcionar como interface entre o performer e o espectador. Terá compreendido nessa altura que só a partir do momento em que considerasse um «centro», uma «casa», ou um «chão» comum

11 No mesmo texto, «No fim, onde tudo aconteceu», Fiadeiro refere, em nota de rodapé, que não tem a certeza de onde foi buscar o termo «Composição em Tempo Real». Provavelmente aproxima-se daquilo a que alguns improvisadores como Mark Tompkins ou Frans Poelstra chamavam, em tempos, Composition Instantenée, ou Instant Composition. Mas essa composição instantânea estaria mais ligada a uma ideia de «agir mais rápido que o próprio pensamento», ou seja, não deixando que o pensamento reflexivo interferisse nas escolhas (cf. Coelho, 2010: 13). Fiadeiro começou a afastar-se dessa velocidade quando percebeu que recorria, quase sempre, a padrões implícitos. Posteriormente, Tompkins adoptou também a formulação Real Time Composition para os seus workshops. No entanto, as abordagens de Fiadeiro e de Tompkins são muito distintas. Por isso chamo ao método de Fiadeiro «CTR», tal como ele e alguns colaboradores fazem, muitas vezes. Neste campo valerá a pena estudar a influência directa, ou indirecta, que John Cage teve nalguns improvisadores da área da dança no uso de expressões combinando variações da ideia de «instante», «no momento», «em tempo real», nomeando «composição» e «improvisação», que tanto significam situações semelhantes como assinalam várias subtilezas de abordagem: seja por via da tradição do Black Mountain College - de onde sai o workshop de Robert Dunn, encontro apresentado na história da dança pós-moderna, como um desencadeador do Judson Dance Theatre, do Grand Union Group e do Contact Improvisation -, seja por via dos músicos improvisadores, no caso de Fiadeiro, no trabalho com Miguel Azguime, com Nuno Rebelo, Vítor Rua, entre outros, que também trabalharam com Tompkins, seja ainda pela leitura directa dos textos de Cage e do acompanhamento do seu trabalho. 
poderia testar a elasticidade das suas fronteiras. Terá compreendido também que, se não existisse um pretexto, não existiriam erros. Tudo o que acontecesse em cena seria absorvido e integrado na realidade da peça. $\mathrm{O}$ erro transformou-se na sua principal matéria de trabalho, erro diante do qual espectador e performer passariam, idealmente, a estar em igualdade de circunstâncias, ambos presentes, testemunhas e cúmplices do nascimento e da morte de um gesto. Ainda no mesmo texto de 2002, a CTR aparece como uma técnica de espera. O intérprete torna-se um mestre da espera aceitando a condição de nunca vir a saber ao que vai, até ao momento em que encontra finalmente alguma coisa, no fim, onde tudo aconteceu (Fiadeiro, 2002 apud Coelho, 2016: 200).

No texto «Praças» - de 1996, também por publicar e a propósito de um projecto que nunca se concretizou ${ }^{12}$-, o programa para um método possível é bastante mais ambicioso, no sentido de não se cingir à arte e ao trabalho de autor-intérprete, mas pensando em abarcar a vida («o filme da vida» e a cidadania). ${ }^{13}$ Estes primeiros textos sobre CTR, entretanto ultrapassados por outros mais recentes, conservam pormenores de linguagem dignos de nota - como o cuidado em especificar que se trata de uma «arte viva», uma vez que não se limita a um território, ou a uma área artística definida e que exige a presença simultânea do criador e do espectador, preferindo espaços polivalentes, por oposição a salas de teatro clássicas, ou de um «filme da vida» que tenta uma «definição radical de presente», aquele que se passa em tempo real, ou seja, aquele que está a acontecer no momento antes de ser exteriorizado. ${ }^{14}$ Fiadeiro sustenta esta posição numa altura em que se «banalizou a apresentação de obras que, ao entrarem em contacto com o espectador, apresentam um grau excessivo de eficácia e de segurança» desvirtuando grande parte da razão de ser desse contacto, a saber: a vivência, o testemunho, a partilha do risco e da fragilidade (idem, 201). «Agarrar» o tempo real não seria o

O projecto Praças estava previsto para a EXPO'98, plano que ficou suspenso por uma tomada de consciência - que já vinha de trás, consequência da participação na programação da Feira do Livro de Frankfurt de 1997 - pelo facto de a NDP (Nova Dança Portuguesa) «[...] estar a ser usada apenas em eventos de grande visibilidade europeia, sendo ignoradas todas as reivindicações, tanto da APPD (Associação Portuguesa para a Dança) como de alguns artistas em nome individual, como Fiadeiro, que lutavam por infra-estruturas, programas de apoio regular e estratégias de sustentação do tecido cultural e artístico, a longo prazo, em Portugal» (Coelho, 2016: 200). veu no AND_Lab entre 2011 e 2013, em conjunto com o trabalho de Fernanda Eugénio.

14 O ano de 1998 marca uma inflexão no trabalho de Fiadeiro. É o ano da polémica com a EXPO'98 que inibiu o avanço do projecto Praças, mas também de outro acontecimento paradigmático: a apresentação de On the Edge, Paris, evento de improvisação de e com Mark Tompkins, Frans Poelstra, Vera Mantero, Steve Paxton, Lisa Nelson, Julyen Hamilton, David Zambrano, Nuno Rebelo, Marco Franco, 1998 - no qual Fiadeiro colabora com os seus pares. 
seu objectivo, nem isso seria possível, mas sim encontrar um equilíbrio entre a oferta de vivências artísticas, tanto para o espectador como para o artista, de forma a produzir uma maior aproximação e a «sensação de que vivemos num mesmo filme: o filme da vida» (ibidem). Este projecto seria feito com colaboradores em residências artísticas em três cidades. Em cada cidade, a praça pública ${ }^{15}$ seria o ponto de partida para quatro «objectos» que produziriam uma relação temporal própria com o espectador: o processo seria um zoom (aproximação em zoom in); o espectáculo, o tempo real; a instalação, a câmara lenta; e o livro, o não-tempo. A síntese de todo este processo seria apresentada na EXPO'98.

O facto de o termo dança aparecer durante a exposição deste projecto justifica-se porque tem sido este [...] o eixo do meu trabalho. Mas a própria evolução desse trabalho tem-me levado a sair da fronteira mais tradicional a que o termo nos remete e talvez fosse mais correcto usar a expressão «Arte Viva» [...] porque sei que é nesse território que pode evoluir a minha linha de trabalho. De qualquer maneira prefiro manter o termo «dança» para tornar mais clara e acessível a afirmação de que é dentro de cada área que a evolução deve acontecer, mesmo que o «desembarque» de todas elas seja no mesmo porto. Tal como tem acontecido com outras áreas da arte contemporânea, tenho tido necessidade de me «contaminar», fundindo no meu trabalho conceitos que fazem parte do pensamento contemporâneo, quer no domínio artístico quer no domínio científico. O tema base do meu trabalho, actualmente, é simples: fala do tempo e do espaço e de como ele é vivido e ocupado por pessoas... hoje. O meu intérprete está constantemente presente. Encontra-se sempre numa situação em que tem de justificar a sua presença mesmo que pense não estar numa posição relevante. Tal como na vida, não é por fecharmos os olhos que deixamos de existir e, por isso, evito os subterfúgios que um teatro proporciona para escondê-lo, ou fazê-lo desaparecer caso não precise dele. Essa tentativa de despojamento convida o espectador a fazer uma espécie de montagem em tempo real do «filme» que ele quer ver. [...] Ao tentar entregar ao espectador a responsabilidade da forma final, estou a fazer com que ele se confronte consigo mesmo e com as suas decisões, entregando-Ihe assim a responsabilidade do olhar. (Fiadeiro, 1996 apud Coelho, 2016: 202) 
Dezanove anos depois, numa entrevista publicada no blogue CoffeePaste $^{16}$, Fiadeiro explica o método CTR como ferramenta que isola o tempo que decorre entre o momento em que somos estimulados por algo, em que há uma inclinação na direcção de algo que nos afecta, e o momento em que agimos perante essa coisa que nos afecta, o momento em que materializamos um afecto seja por uma palavra, um gesto, etc. A duração entre o momento em que se é afectado e o momento em que nos relacionamos com esse afecto «pode ir de meio segundo a meio minuto, a meio dia, a meio ano» (Fiadeiro apud Coelho, 2016: 202).

Quer dizer, depende do delay. Mas acontece em qualquer escala, está a acontecer aqui na nossa conversa e está a acontecer numa escala mais macro, sempre. Portanto, esse delay (entre o afecto e a execução) existe sempre. [...] A dimensão da composição, na verdade, é o com-por, ou o por-com. É a dimensão da relação com o outro, que podes ser tu próprio [...]. Claro que eu só posso formular isto, desta maneira, agora passados vinte anos de investigação sobre isto, porque na altura era uma coisa que me apanhava. E que acontecia porque, no acto de improvisação, em estúdio, para encontrar matéria de composição e dramaturgia, eu verificava que a ideia de liberdade associada à improvisação, à ideia de «porque improviso, eu sou livre» estava muito longe de ser verdade. E eu identificava isso no meu próprio corpo. Percebi que havia um conjunto de hábitos, que havia uma estrutura de poder, digamos, no modo como eu percepcionava o real que me fazia reagir às coisas. Não digo «sempre de determinada maneira», mas baseada e sustentada sempre no mesmo género de leitura, ou de interpretação da realidade. E quando percebi isso foi um choque [...]. Mas depois vou mais a fundo e apercebo-me que essa estrutura de poder - que todos nós carregamos, tem que ver com os nossos hábitos, com os nossos medos, e com o modo como tendemos a repetir aquilo que já conhecemos -, pode ser desactivada. Mas é preciso trabalhar para isso. Deixar uma pessoa livre, sem que ela própria construa restrições e limites de relação com os seus próprios impulsos e com as suas próprias vontades e desejos, não é a melhor forma de desactivar essa estrutura de poder. (ibidem)

Terá sido com esta percepção que Fiadeiro começou a desenvolver lentamente um método com um conjunto de princípios, que se praticam 
em várias escalas e com vários tipos de pessoas, bailarinos ou não. Uma das principais qualidades que se pratica e desenvolve na CTR é a capacidade de inibir o impulso, para conseguir criar uma distância perante o afecto que permita mapeá-lo e colocá-lo numa espécie de topografia das relações. Um outro aspecto considerado muito importante é a capacidade de se identificarem, nesse mapeamento, as «relações entre relações». ${ }^{17}$ Tendemos a criar relações entre posições. «Poder ver as relações de relações é uma ferramenta que permite observar, em cada momento, aquilo que pensamos que já sabemos. É uma ferramenta proposta para nos protegermos de nós próprios» (ibidem).

Há uma transferência clara do protagonismo do sujeito para o acontecimento. E um acontecimento é uma relação entre relações. Tudo isto foi traduzido em modo de jogo de improvisação que eu pratico em várias plataformas. Essas escalas distintas, de $5 \times 5$, em que o corpo se pode envolver, por exemplo, de $1 \times 1$ só com objectos, com implicações diferentes. E depois poder trabalhar com artes, ou com sistemas complexos, etc. [...] A partir do momento em que inibo o impulso, ou o hábito, eu estou a provocar novos padrões neuronais, e é a isso que «eles» (pessoas que trabalham com sistemas complexos) chamam criatividade. 0 «manusear» por oposição ao «manipular» requer uma atenção ao presente e à construção de uma ética da relação com esse presente, não o usando como dado adquirido. (ibidem)

No capítulo «If you don't know, why do you ask? An introduction to the method of Real-Time Composition» (2007), Fiadeiro recupera o episódio de uma polémica levantada, na televisão portuguesa, a propósito de um comentário seu que propunha desvincular a associação do corpo com a dança, como mote para uma questão que já seria óbvia entre «pares». Recuperando a afirmação/provocação «A Dança não passa pelo corpo», faz um trajecto também pelas discussões da rubrica «O que faço diz-te alguma coisa?» programada com artistas e pensadores para o Lab 9 de 1999 (cf. Guéniot/RE.AL, 200o).

O que eu quis e quero dizer é que o corpo não é mais fundamental para a dança do que é, digamos, para a literatura, para a fotografia, para as 
artes visuais, ou qualquer outra forma de arte. Apenas quis dirigir a atenção para a urgência da comunidade que vive e respira e pensa em dança de reivindicar este espaço, de tirar a dança para «fora da sua concha», de uma vez por todas, «desencorporando-a», por assim dizer, e contribuindo, assim, para um debate de pesquisa genuíno - um debate que não estivesse apenas preocupado com a marcação de território. (Fiadeiro apud Coelho, 2016: 203-204)

Como circunscrever um afecto? Fiadeiro construiu a peça I Am Here (2003) a partir de um afecto, não sabe qual exactamente, mas o processo foi gerado algures na relação com o trabalho de Helena Almeida. Um trabalho, um convite para uma inauguração, um texto, várias fotografias. O texto: «Olhamos para o corpo e o corpo termina de repente nos pés, nas mãos. Acaba ali. Não há mais nada à frente, parece uma escarpa de um rochedo sobre o mar. De repente termina» (Almeida apud Fiadeiro, 2014). ${ }^{18}$ Já havia uma execução inscrita naquela matéria e havia uma enorme potência de relação. Grande parte do investimento foi feito, por isso, no método e não na matéria. Fiadeiro comprou os livros sobre e com os trabalhos de Helena Almeida. Ligou-lhe. Visitou o seu ateliê, consultou os seus arquivos. Foi para o estúdio trabalhar com a frase sobre os limites do corpo. Tirou fotos de si próprio no escuro, projectou-as na parede e desenhou o seu contorno. A primeira sombra apareceu no ecrã como um efeito colateral. Não ignorou esse acidente. Continuou a saborear o processo de circunscrição de um afecto por aproximações. Usou vários trabalhos de Almeida. Uns tinham pigmento azul, outros rastos e sombras. Uma série de fotos de 1996 foi ficando. Uma sombra sem cabeça que vai desaparecendo? Começou a trabalhar com o pigmento que Almeida usava nas fotos a preto-e-branco e que parecia fazer de sombra. O mesmo pigmento visto ao vivo não era tão interessante, era cinzento e demasiado leve, espalhava-se por todo o lado. Tiveram de procurar outros pigmentos. Em conversa com Almeida, Fiadeiro percebeu que a fotografia com a sombra afinal... «Qual sombra?», aquilo era um vestido, para Almeida. Foi o mal-entendido ideal para ganhar uma maior distância em relação à peça de Almeida. Afinal era uma tendência mais Lourdes Castro/Manuel 
Zimbro (cf. À Luz da Sombra, 2010) que Fiadeiro explorava, estes mais «obcecados» com sombras e contornos. O trabalho afinal não era «sobre», era «com» o trabalho de Almeida. No estúdio, tentou traduzir a imagem produzida por Helena Almeida. Se a «sombra» de Almeida era uma série em que se ia rarefazendo o pigmento, como se chegava lá, ao vivo, e em tempo real? A sequência de fotos de Almeida era o seu script (guião). A primeira tentativa de Fiadeiro foi espalhar o pigmento com os pés no escuro. O resultado não foi satisfatório, nem no tipo de mancha deixada, nem no tipo de consistência, peso ou cor do pigmento. Mas descobriu que o som, no escuro, era importante e apanhou-se a dançar no escuro. Passou a ser muito importante dançar no escuro, pois ultrapassou um desconforto que foi ganhando ao longo da sua carreira com o facto de dançar para um público. Tudo isto estava conceptualmente ligado ao lugar onde estava. E ajudou-o a não «desenhar» esse rasto. Uma vez focado na dança, o resultado seria o desenho da dança, um rasto, e não uma coisa programada. Para fabricarem a sombra com o pigmento - fê-lo com a ajuda de Ana Borralho, João Galante e Marie Mignot, participantes activos neste processo -, instalaram um foco de luz, fizeram o contorno da sombra e depois preencheram-na com pigmento. Processo que passou a durar, aproximadamente, uma hora, depois de experimentado várias vezes. Passadas algumas semanas, descobriram um pigmento com resultados mais semelhantes à fotografia de Almeida, mas ao vivo (óxido de ferro). No final, a sombra que servia de molde acabou por ser incluída no trabalho. E a imagem icónica the I Am Here tem que ver directamente com essa sombra. ${ }^{19}$ No escuro, durante a dança que espalha o pigmento gradualmente, é tirada uma foto, uma flashada de Walter Lauterer, que vê Fiadeiro dançar com uma câmara de infravermelhos. Quando a luz regressa à sala, Fiadeiro é apanhado parado, mas com um braço fora da sombra ${ }^{20}$, de onde caminha para desenhar o contorno da foto tirada e projectada no papel de cenário em frente. Depois de desenhar o contorno do seu corpo, Fiadeiro volta para o seu posto de figura com sombra fixa. Uma personagem que resultante da luz a incidir no corpo de Fiadeiro, de costas e de pé. Até ao momento em que as luzes mudam e a sombra continua igual, e depois, até ao momento em que Fiadeiro sai daquele sítio e a sombra permanece. O resultado é «estranhamente inquietante» e pode ver-se no vídeo aos 4'52": I Am Here em https://vimeo.com/116156883.

Na primeira vez que a luz regressa depois do escuro, em que é tirada uma foto, Fiadeiro não saiu do seu lugar, apenas se moveu permitindo à câmara apanhar, por exemplo, um braço. No momento em que sai desse lugar, para desenhar o contorno do braço projectado que acabou de ser fotografado, mesmo que o público já tenha reparado que o pigmento no chão não é a sua sombra, há um efeito de surpresa. Como se ele estivesse, de facto, a afastar-se da sua sombra. 
lembra Peter Schlemihl, do conto de Adelbert von Chamisso (2005 [1814] $)^{21}$, evocando uma potência de sombra que fica fixa num lugar, destacando-se do corpo, como um eco dos princípios da fotografia, ou das mãos em negativo em Les mains negatives, de Marguerite Duras (1979). «As mãos negativas» de Duras surgiram como tema, no mesmo workshop de 2014, citadas por Adaline Anobile, a propósito do filme $\mathrm{e}^{22} \mathrm{e}$ das mãos negativas inscritas nas grutas pré-históricas. São os microfones, que registam e amplificam o som da dança, que nos dão conta de esta ser uma dança «vivida fisicamente», estafante, do "ponto de vista» sonoro. A imagem captada no escuro, do corpo em movimento, por vezes no ar, é projectada na folha de papel de cenário, onde Fiadeiro vai desenhar repetidamente o contorno da projecção. E aqui a colaboração do cenógrafo Walter Lauterer terá sido fundamental. A folha de papel de cenário onde se projecta a sombra que tem a consistência densa de uma boa camada de pigmento de óxido de ferro, no chão, é a continuação da mesma que faz o plano vertical, onde se projecta a imagem do corpo que dança, captada no escuro, e onde é delineado o contorno dessa projecção.

Foi Lauterer quem propôs que estas duas imagens funcionassem juntas - a sombra materializada no chão e a projecção da imagem fotográfica no plano vertical -, daí saiu a solução para parar de dançar. Era o flash da câmara que parava a dança no escuro, logo de seguida, a imagem fotografada ficava projectada para que ele pudesse sair de onde estava e ir desenhar o seu contorno, o contorno do seu corpo (uma evocação do texto inicial de Almeida). Lauterer, com a câmara de infravermelhos vê Fiadeiro a dançar no escuro e escolhe o momento em que tira a foto com o flash, talvez apanhando Fiadeiro suspenso no ar, ou no meio de um movimento estranho. Durante o processo, numa das primeiras tentativas de levantarem o papel de cenário, o pigmento começou a acumular-se numa tirinha da dobra do papel, por um lado, e a revelar os rastos da dança na sua superfície, por outro. Essa descoberta leva-os a escolher mostrar a dança enquanto rasto, no papel. O papel deveria subir até à vertical desse lado também para que o rasto se tornasse visível. Como seria se o papel de cenário continuasse a subir além da altura dos braços? Depois dessa exposição do desenho da dança, o pigmento que restava no excesso de papel, entretanto cortado, era a matéria que Fiadeiro tinha para trabalhar. Esse resto é dobrado segurando o pigmento dentro do

21 No capítulo de Jacinto Lageira, «João Fiadeiro Repli dans le noir» (Lageira, 2013), o autor faz também uma associação da sombra de Fiadeiro ao conto de Chamisso.

Marguerite Duras, Les mains négatives, in https://www.youtube.com/watch? $=$ rQCgl-QH-Uk. 
«embrulho» de papel e levado para fora do dispositivo, onde o chão é negro também. Nesse lugar fora do «cenário» inicial, Fiadeiro volta a desdobrar o papel de cenário que transportou o pigmento e depois cobre-o com o pigmento preto, devolvendo o quadrado preto a um fundo preto para logo cobrir tudo o que se vê, do seu próprio corpo, com o pigmento preto, entrando para o quadrado preto, como um buraco negro todo preto deitado, aninhado, quieto até que a luz desaparece num fade out lento, até ao negro total. Cenograficamente, o dispositivo imaginado por Lauterer funcionou com uma folha de papel de cenário enorme (ou duas folhas unidas imperceptivelmente) e levantada em cada uma das pontas formando uma diagonal em relação ao público.

Nesta peça de luz e sombra, de negativo e positivo, de projecção, corpo, contorno, rasto, dança e buraco negro, o pensamento coreográfico emerge várias vezes. O rasto coreográfico deixado na folha de papel é de uma dança que se inscreve no escuro, talvez o lugar da inocência, indistinção e imanência, onde alguns bailarinos-coreógrafos-improvisadores gostariam de ir parar mais vezes, sendo «apanhados» em queda, em lugar de manipular esse desígnio-desenho. $\mathrm{O}$ desenho que fica como marca da «grafite» deixa o «gráfico» de «coreo-gráfico» mais amparado semanticamente: uma khoreia (dança) graphein (gráfica)? O pigmento de óxido de ferro usado em I Am Here é, por coincidência (ou não), um dos materiais usados para inscrever as pré-históricas «mãos negativas» em várias grutas. Podemos pensar, então, não só em sulcos na pedra - para onde nos inclinaríamos pensando em «gravar» as «garras» de «grafia»»3 -, mas também na produção de imagens negativas e positivas do corpo (uma ideia mais fotográfica). É do contorno de partes do corpo que a peça trata também, apanhadas no escuro, numa dança com poucos referentes, as projecções do corpo na folha de papel são posteriormente fixadas num contorno feito à mão. É a dança que destrói, finalmente, a ilusão de óptica do pigmento composto em forma de sombra, ao mesmo tempo que se inscreve em rasto, na folha de papel. A dobragem da mesma folha de papel vem «complicar» ${ }^{24}$, ou complexificar o traço, no sentido em que a inscrição se dobra e redobra fazendo do traço simples uma sobreposição de traços, ou antes, a sobreposição do pigmento. Na desdobragem regressamos a uma qualquer clareza literal, de performance (2013-2015), desdobrando uma série de hipóteses trabalhadas com Le Pli (Deleuze) e por Eugénio e Fiadeiro a partir de Deleuze (ver também Lageira, 2013). 
agora podemos ver e tratar um plano horizontal negro, no chão negro, com um corpo negro de homem desaparecendo, como desaparecem as sombras dentro de outras sombras mais negras e sobrepostas, sumidas no escuro que tudo absorve evocando o «buraco negro», ou o «poço dos negros», ou ainda - como Lepecki poderia dizer também -, «o porão do navio dos negros» (cf. Lepecki, 2014). «Poço dos Negros» é o nome da rua em que se fixou a RE.AL em 2005 e onde estará até 2019.

AND_LAB E MODO OPERATIVO AND (2011-2014)

A convivência com os três anos de oficinas e de actividades conjuntas do AND_Lab de Fernanda Eugénio e João Fiadeiro fez com que a mistura do trabalho de Composição em Tempo Real de João Fiadeiro, que tenho vindo a citar, com a Etnografia como Performance Situada de Fernanda Eugénio, também combinada com o seu trabalho de pós-doutoramento - que concretizou em simultâneo com o desenvolvimento do Modo Operativo $A N D$-, seja descrita por mim como um todo, que não é homogéneo, mas que neste intervalo de tempo funcionou como tal. AND_Lab foi o nome encontrado para designar simultaneamente o Anthropology and Dance Laboratory, com a palavra «and» tirada da proposta de uso iterativo do «e», no trabalho de Eugénio (2006), mas em inglês, para que fosse reconhecível num contexto internacional mais alargado. ${ }^{25}$

«O contacto-improvisação fez-me perceber muito do que faço hoje», conta Fiadeiro no início do workshop MO_AND (2011), «até que um dia, estava a dar um workshop de contacto-improvisação e pedi uma mesa. ${ }^{26}$

25 As oficinas AND_Lab de Eugénio e Fiadeiro aconteceram sobretudo no Brasil e em Portugal. As oficinas de Modo Operativo And e o AND Lab I Centro de Investigação de Eugénio e cia. continuam a cumprir e a alargar essa rota fixando grupos de trabalho locais (2015-2019). Fiadeiro privilegiou o regresso à designação $C T R$, desenvolvendo algumas das práticas e discursos que saíram do seu encontro com Eugénio com outros colaboradores mais recentes, como Romain Bigé (cf. Fiadeiro, 2018).

ula teórica à volta de uma mesa é uma modalidade de transmissão utilizada desde o princípio de 2000 que, segundo J. F., permite estabelecer um ponto de partida "real" e social para o trabalho no estúdio, subtraindo dos corpos dos performers o excesso de informação criado pela apreensão de técnicas e de modos de relação específicos à prática de dança contemporânea. [...] A mesa é para J. F. um primeiro passo na direcção de uma equivalência entre espaço real e espaço de trabalho artístico, o que permite reformular a dicotomia tradicional que estabelecemos entre realidade (vida) e ficção (teatro). O dispositivo mesa é uma espécie de arquétipo da realidade, arquétipo do corpo quotidiano. Ela serve realmente e funcionalmente para discutir a CTR, mas ela produz ao mesmo tempo um afastamento face aos modelos incorporados por anos de pesquisa em dança (o estúdio como lugar de dança "nua", de "pés descalços" e de "pijamas da dança"). Ela anula também a separação tradicional entre práticas verbais e não verbais [...]. A mesa é, portanto, um ponto de partida [...]» (excertos de texto inéditos de Rita Natálio sobre CTR, 2007-2008: 11). 
No dia seguinte, só tinha três pessoas no workshop e aí começámos a “trabalhar” (Fiadeiro, 2011). Esta narrativa relatando o início de um novo modo de trabalhar - que seria o método de Composição em Tempo Real, nos anos 90, depois da exaustão do contacto-improvisação - foi usada também como forma de actualizar um outro começo, a introdução de um novo modo, ainda incipiente, em 2011, o Modo Operativo AND, que Fiadeiro trabalhou com Eugénio entre 2011 e 2013. «Interessa-me o trabalho em comunidade e o contacto-improvisação tendia muito para o trabalho a dois», continua Fiadeiro (ibidem). Este $A N D_{-} L a b$ produziu workshops com vários formatos que, dependendo da intensidade e do objecto, faziam variações da palavra «AND» (AND_Tools, AND_Craft, $A N D \_$Research, WeekAND, etc). Este laboratório AND seria também um certo regresso a processos para «gerar comunidade» que teriam sido abandonados por Fiadeiro, em 2007, quando deixou de coreografar. «O acto de criar um espectáculo ia contra o processo de não concluir um processo» (ibidem). No arranque do trabalho, «estar junto» foi a relação privilegiada e praticada em cada jogo. Dentro de «estar junto» destrinçam-se as possibilidades de uma relação se tornar ou complementar, ou simétrica, ou hierárquica (cf. Eugénio, 2006). Para observar as relações, o jogo abrandou a «realidade», criou uma maqueta e propôs-se funcionar por etapas, ou por «posições»: como não temos hipótese de criar os vários futuros possíveis, cria-se um modelo onde estes se vejam como «mundos virtuais», i.e. levantam-se várias hipóteses de relação, antes de elas se concretizarem. A maqueta consiste num enquadramento, ou literalmente, num quadrado marcado com fita crepe, no chão. Um quadrado de $1 \times 1$ produz um mundo maqueta à escala das mãos e de pequenos objectos. Quando muda a escala, por exemplo para $2,50 \times 2,50$, já podemos entrar numa maqueta de corpo inteiro. Como se fosse um jogo de tabuleiro que muda de escala. Mas, à medida que a escala aumenta, aumenta também a vertigem. $\mathrm{Na}$ «escala corpo» entramos embriagados de ideias e de coisas para fazer «sempre que estamos à espera, há como que um shot de dopamina que nos premeia em cada concretização de uma expectativa» (ibidem). A «escala corpo» corresponde à possibilidade da entrada dos jogadores em «campo», ou seja, dentro do quadrado, ou do enquadramento.

O jogo começa pela sensibilidade às condições iniciais, ou SIC, abreviando e em inglês ${ }^{27}$, a que tenho chamado também «reparagem», num 
misto de dupla paragem e de repérage cinematográfica (a partir do «re-parar» usado por Eugénio e Fiadeiro). «O que é que a coisa tem?» (o que é que existe para ser reparado?) é a pergunta a fazer, contornando a questão, mais comum: «o que é que a coisa é?» (não é ainda, pois está em potência de relação, está em devir). Neste momento de sensibilidade às condições iniciais, gerir o tempo é poder abrandar para «desobviar» (desobstruir a atenção, não dar por garantido o que parece óbvio). A gestão do tempo deve dar lugar à criação de hipóteses de relação. A affordance aparece aqui então, como possibilidade perceptiva ligada à teoria de Gibson (1986 [1979]). O que quer que exista, o que quer que a coisa tenha, algo convida à relação, é uma «convocância», uma «possibilitância», ou a propriedade de aumentar as possibilidades de acontecimento (cf. Eugénio). Apostando na co-incidência, em lugar de aceitar um qualquer acaso, o Modo Operativo AND de Eugénio e Fiadeiro privilegiou as estratégias para «não ter uma ideia» à partida, de ensaiar modos de «viver juntos» e de «adiar o fim» sem ter de sustentar um modo de «vida miserável», i.e. «aceitar o fim» (vulgo: não entrar em negação). «Estar com» será diferente de estar à espera, de ter expectativa, e o «com»é visto como uma das componentes da com-posição, para estes autores. Portanto, o jogo estabelece-se por via de uma primeira proposta de posição à qual uma outra pessoa do grupo junta uma segunda posição, formando a primeira com-posição, que é já uma tendência, mas onde várias hipóteses são ponderáveis ainda. Dentro dessas hipóteses, algumas terão maior relevo que outras. Há a relevância do óbvio, por exemplo, se a primeira posição foi introduzir uma cadeira e a segunda posição foi alguém sentar-se nela, uma hipótese com relevo poderia ser uma terceira pessoa introduzir uma segunda cadeira. Mas é antes da terceira posição que o grupo suspende o reflexo de agir imediatamente sobre o jogo comum, para individualmente elaborar um leque de hipóteses que possam simultaneamente ter relevo e aumentar a potência do jogo, por exemplo, inaugurando um plano a partir da tendência gerada na relação de relações anterior que, mais tarde ou mais cedo, instale uma máquina de encontro entre todos os jogadores, uma com-posição-com. $\mathrm{O}$ encontro aqui corresponde ao próprio jogo-acontecimento que alimenta o plano comum, em lugar de serem os jogadores a manipular o jogo individualmente, ou mesmo em grupo. Uma vez encontrados pela máquina do jogo, o grupo concentra-se em sustentá-lo, fazendo jus ao acontecimento. $\mathrm{O}$ tempo do acontecimento tende a dilatar-se para que, em macroescala, se possam prever alguns acidentes e fins possíveis. $\mathrm{O}$ fim corresponde a uma 
evidência comum de que a máquina «fechou?». ${ }^{28}$ Quando se prolonga «artificialmente» o jogo, já alguém, ou ninguém, sabe mais que máquina está a ser alimentada ali e o jogo vai morrendo por si, ou é interrompido por quem não suporta uma «vida miserável». ${ }^{29}$ Normalmente esta situação corresponde a um loop interminável de posições sem «sentido comum» (podemos morrer de tédio, ou de adrenalina...), a isso se chama também, no jogo do $M O_{-} A N D$, não saber «aceitar o fim». O trabalho passa muito por uma prática de atenção, por um lado, e por poder transformar as condicionantes em condições de jogo. Se, por exemplo, a condicionante «ter comichões» nos distrai (ou nos chama a atenção), poder trabalhar com a condição contorcer-se ou coçar-se enquanto jogo. Uma posição que nos conduz para o potencial performativo do jogo e que se desenvolve mais na «escala corpo», mais praticada na CTR do que no $M O_{-} A N D$ até 2014. As escalas de jogo mais pequenas têm a vantagem de poderem ser jogadas com pessoas que não querem pôr o seu corpo em campo, deixando a performatividade para a com-posição dos objectos. Várias vezes, nos workshops em que Eugénio e Fiadeiro trabalharam com cientistas, monitores de museus, ou grupos de artistas e estudantes de várias artes, foi essa a escala de jogo escolhida. Os quadrados desenhados com fita no chão foram transformados em mesas de trabalho quadradas para explicar e jogar o $M O_{-} A N D$, durante um grande período de trabalho de investigação e de workshops também com os grupos que acompanharam mais intensamente o desenvolvimento da ferramenta, como o grupo de Lisboa, no qual eu me incluía. Se uma condicionante for o desequilíbrio dos objectos numa mesa, por exemplo, qualquer desequilíbrio na escala da mesa $1 \times 1$ pode ser transformado numa condição-jogo para trabalhar o equilíbrio, ou a queda.

Uma variante do jogo no quadrado funciona com vários quadrados em simultâneo, jogados a pares. O jogo GHOST, palavra que combina guest (convidado) com host (anfitrião), pode ser jogado com números pares de jogadores, sendo que um jogador se fixa no quadrado de partida (host) e o segundo (guest) circula pelos vários campos (ainda quadrados modo por todos os jogadores. Há um jogo de afectos estéticos (e outros) que subjaz às acções individuais manifestas, e que, muitas vezes é ignorado enquanto subjectivação e criação de discurso. No entanto, quando o plano comum acontece, a satisfação tende a ser inequívoca. clarificação do método. Eugénio, no entanto, evita antecipar o fim de um jogo, mesmo que pareça em muitas etapas insustentável. Os traços da subjectividade de quem propõe um jogo não são muito tidos em conta na teorização das práticas, em geral, no entanto pode ser uma pista para vir a constituir discurso sobre estilos e abordagens no futuro. 
de escala pequena, ou média). Este jogo funciona com os objectos, ou os rastos que ficam nos quadrados, portanto não se presta tanto à acção performativa, pois o convidado seguinte que chegar ao quadrado só terá acesso ao que lá ficou e não à acção desempenhada. Uma vez atribuídos os papéis em cada par, aquele que será o guest propõe uma posição dentro do quadrado. O host observa e faz uma segunda posição que se relaciona com a primeira, e o guest segue o seu caminho para o quadrado de uma outra equipa, onde, mais uma vez, terá um tempo inicial de sensibilidade às condições de relação das posições que vai encontrar; vai fazer o trabalho de reparar para poder propor uma terceira posição, que se relaciona com a relação que observou. Ou seja, propõe uma relação com a relação iniciada pelo outro grupo, à qual o host, após um período de atenção, responde com nova proposta. O jogo prossegue de forma que todos os guests percorram todos os jogos e voltem ao jogo de partida. Observam-se desafios de várias ordens. Um dos desafios para o host é lidar com o facto de a sua tendência «natural» para preservar uma lógica relacionada com a sequência de intervenções, a que só ele assistiu, ser constantemente desafiada, de cada vez que um novo jogador aparece na sua «casa» e vê o que lá está, pela primeira vez. Outro desafio é aquele que se apresenta ao jogador que migra, guest: de cada vez que este chega a um novo campo, tem de lidar com um sistema de relações cujo historial não conhece. Todos estes jogos são feitos sem falar, apesar de a voz poder ser usada como matéria de trabalho - o silêncio é uma estratégia de relação e de atenção. No fim, quando cada guest reencontra a sua «casa», depois de ter passado por todos os quadrados, apesar de haver um jogador que teve o papel de manter uma lógica interna na cronologia das passagens e das posições, ele pode achá-la irreconhecível, ou talvez não. Os jogos mais curiosos ${ }^{30}$ passam, por vezes, por situações em que a máquina que desencadeou um jogo se manteve reconhecível até ao regresso do jogador migrante. Mas não será essa coincidência feliz da manutenção de um jogo aquilo a que poderíamos chamar mestria? E a felicidade dessa recompensa não estará relacionada com a «partilha do sensível» dentro de um plano que se tornou «comum»? 
Se de Exaurir a dança de Lepecki (2017) tiramos a ideia de desaceleração da dança como uma necessidade de crítica à cinética da modernidade, Fiadeiro cita por vezes Bartleby, o Escrivão (Melville apud Agamben, 2007) dizendo corriqueiramente que «preferiria não...». Mas o «não» ${ }^{31}$ de Fiadeiro, essa inibição do fazer, implica uma actividade intensa de pensamento. $\mathrm{O}$ momento em que não se passa nada, antes de alguém agir marcando uma posição, ou uma relação de relações dentro de «um quadro», é o momento de suspensão em que se espera um aumento da potência de um pensamento em grupo. Ninguém diz nada, e quem avança tem a responsabilidade de estar à altura da potência gerada. Muitas vezes o jogo cai aqui, uns precipitam-se, outros esmorecem ou bloqueiam. Talvez seja aqui também que se pode gerar a tecnicidade da CTR. Saber modular a atenção e poder lidar com o tempo da espera dando-lhe dignidade, ou seja, oportunidade para qualquer um dos presentes gerar relações e acontecimentos, é uma mestria, ou uma «arte» que pude observar em performers como Cláudia Dias, Márcia Lança, Gustavo Sumpta, João Fiadeiro, etc., mas também em Rui Catalão, que quando começou era jornalista, ou em Fernanda Eugénio, mais conhecida como antropóloga, que colaboraram activamente com Fiadeiro entre 1999 e 2011 (em períodos diferentes).

\section{RE-EXISTÊNCIA}

Existência | aicnêtsixE... Para lá de... Para cá de... Como se o reflexo na superfície espelhada se afinasse pelas distâncias e vontades, imagem intangível, mas reprodutível, reprodutível, reprodutível. ${ }^{32}$ Um limiar instável que projecta e reflecte em lugar de conter. Limiar transponível reversamente para o passado e para o futuro, em loop na mesa de montagem do tempo real. A contenção, no espelho, é iludida, ou posta em abismo. O enigma por resolver na percepção não nos permite apenas

No contexto de uma história da dança, o «não» fará sempre ressoar o «Manifesto do Não», de Yvonne Rainer (1965). 
reconhecer imagens como representação, mas exige do olhar, olhar de novo, parar e re-parar, distrair um pouco a atenção, apagar a luz, desligar a lucidez e a reflexão, re-existir como se fôssemos o reflexo de um outro. Jogar. Aquilo que afecta e complica a vida como matéria de jogo. «Isso», o escuro, o que nos perturba, mas que não conseguimos «agarrar», é a matéria que propulsa a investigação. Seja narcisismo, ou enigma da percepção, «isso» dá trabalho e fornece matéria para trabalhar.

Como se a queda fosse o paradigma subjacente ao acidente feliz, o contrário da paralisia da reflexão, como uma entrega: falling in love. Como se um método artístico fosse uma «ginástica» no impasse da reflexão para não paralisar a poética e o pensamento «livre» de ideias pré-concebidas («Como não ter uma ideia?», «Como viver juntos?», cf. Eugénio e Fiadeiro, 2013). O antídoto seria uma possibilidade de metaestabilidade quando o processo tende a encerrar-se, ou em excesso reflexivo, ou em excesso de fusão. A reflexão entendida como matéria de investigação poderá ser uma estratégia para ultrapassar impasses de fusão. Na «queda sem fim» (cf. Miranda, 2006) da vida, pode fazer-se recortes, novas estruturas/condição, outras possibilidades de ver qualquer coisa a partir de um «fora» hipotético, posto à nossa frente, como na folha de papel, no dispositivo de palco, ou no dispositivo cinematográfico, claramente visível. A coreografia poderia ter esse papel de dividir para «ver». Mas também de «dividir para reinar», convocando o seu papel organizador, lugar de comando e de controlo, de poder coreopolítico: prescritivo e descritivo, tal como é explorado por Lepecki (2017), e também o seu mecanismo de convite e de troca no jogo da dádiva e contradádiva, a reciprocidade metódica como sugerem Lisa Nelson, Eugénio e Fiadeiro. Como se a queda do contacto-improvisação, uma queda defendida cientificamente em Fall after Newton (Paxton, 1987) fosse também um antídoto possível para uma entrada na inevitabilidade da coreografia vista de fora, desenhada visualmente antes de se pôr em prática. Estamos ainda a tratar da física de Newton e das leis que convoca para se defender do caos. Mesmo assim, muito diferentes da entrega a um mundo desconhecido. Métodos para ver e para investigar a queda. Métodos para destrinçar a velocidade em ritmos e densidades, massas de relação que emergem na duração.

Em O que fazer daqui para trás (Fiadeiro, 2015), não está ninguém em cena, senão quando, exausto, um dos performers pára de correr para falar connosco. O esgotado (cf. Deleuze, 2010) de Fiadeiro poderá ser também um resultado de não se poder mais com uma repetição previsível: 


\begin{abstract}
um palco e uma expectativa de entrar e sair de cena para... O que o performer disser ao microfone será dirigido em sopro de cansaço aos presentes. Um sopro que indicia o princípio de um desfasamento, a possibilidade de que algo se esgote e que, de outros extractos, emerjam novos encontros.
\end{abstract}

\title{
REFERÊNCIAS BIBLIOGRÁFICAS
}

AgAmben, Giorgio (2007), Bartleby, escrita da potência, Lisboa, Assírio \& Alvim.

CH Amisso, Adelbert von (2005), A história fabulosa de Peter Schlemihl, Lisboa, Assírio \& Alvim, [1814].

COELHo, Rita Lucas (2015), blogue CoffeePaste, entrevista com João Fiadeiro, http://coffeepaste.com/joao-fiadeiroentrevista.

Coelho, Sílvia Pinto (2016), Corpo, imagem e pensamento coreográfico, da pesquisa coreográfica contemporânea enquanto discurso, tese de doutoramento, Faculdade de Ciências Sociais e Humanas da Universidade Nova de Lisboa, https://run.unl.pt/handle/10362/21393.

- (2018), « «Práticas de atenção»: ensaios de desterritorialização e performance coreográfica», in Cadernos de Arte e Antropologia, n. ${ }^{\circ}$, vol. 2, A operacionalidade do jogo, https://journals.openedition.org/cadernosaa/1595.

DE LEuZE, Gilles (1991), A dobra: Leibniz e o Barroco, Brasil, Papirus [1988].

- (2004), «A intuição como método», in O Bergsonismo, São Paulo, Brasil, Editora 34, [1966].

- (2010), «O esgotado», in Sobre Teatro: um manifesto de menos: O esgotado, Rio de Janeiro, Jorge Zahar.

DELEUZE, Gilles e GUATTARI, Félix (2004), «6.28 de Novembro de 1947-Como construir um corpo sem órgãos?», in Mil planaltos, capitalismo e esquizofrenia 2, Lisboa, Assírio \& Alvim, [1972].

DURAs, Marguerite (1979), Les mains négatives, https://vimeo.com/7475873.

EUGÉNIO, Fernanda (2006), «O “e” como estilo de vida», Hedonismo competente. Antropologia de urbanos afetos, tese de doutoramento, Rio de Janeiro, PPGAS, Museu Nacional.

EUGÉNIO, Fernanda e FIADEIRO, João (2012), Conferência-performance Secalharidade, Lisboa, Culturgest.

- (2013), «O jogo das perguntas, re-parar: da mobilização infinita à mobilização ilimitada», in Actas do Colóquio Movimento e Mobilização Técnica, CECL, Faculdade de Ciências Sociais e Humanas da Universidade Nova de Lisboa.

- (2013a), O encontro é uma ferida, Lisboa, GHOST.

- (2014), Sensibilidade às condições iniciais, AND_Lab, https://vimeo.com/album/3524990.

EUGÉNIO, Fernanda e SEIÇA SALGADO, Ricardo (2018), «O AND é jogo? Ensaio-conversa à volta da operacionalidade do jogo no Modo Operativo AND», Cadernos de Arte e Antropologia, vol. 7, n. ${ }^{\circ}$, http://journals.openedition.org/cadernosaa/1545.

FIADEIRO, João (1998), «... agimos depois de compreender ou compreendemos depois de agir?», in Theaterschrift, número extra, Dezembro de 1998, Intensificação: performance contemporânea portuguesa, pp. 61-77.

- (2002), «No fim onde tudo aconteceu (O local para onde nos dirigimos, só o conhecemos quando lá chegarmos)», inédito.

- (2003), «O negativo de mim próprio», Imagem e Vida, Revista de Comunicação e Linguagens n. ${ }^{\circ}$ 31, Faculdade de Ciências Sociais e Humanas da Universidade Nova de Lisboa, pp. 199-200.

- (2003a), I Am Here, https://vimeo.com/116156883.

- (2007), «If you don't know, why do you ask? An introduction to the method of Real-Time Composition», in Knowledge in Motion Perspectives of Artistic and Scientific Research in Dance, ed. Gehm, Huseman e Wilcke (transcrição).

- (2015), O que fazer daqui para trás, https://vimeo.com/138306335.

- (2018), Composição em Tempo Real, anatomia de uma decisão, Lisboa, GHOST. 
FIADEIRO, João e FIADEIRO, Inácio (1996), «Praças», inédito.

FIADEIRO, João e GUÉNIOT, David-Alexandre (2002), «Entre moi et moi-même, entre réalité et fiction, entre ici et lá, essai de transcription du travail de recherche de João Fiadeiro», in Claire Rousier (dir.). (2002), La danse en solo, Paris, Centre National de la Danse, pp. 115-124.

GIBSon, James J. (1986). «The Theory of Affordances», in The Ecological Approach to Visual Perception, Nova Jérsia, Lawrence Erlbaum Associates, Inc. Publishers, [1979].

GUAT TARI, Félix (1993), Caosmose, Um novo paradigma estético, Rio de Janeiro, Editora 34.

GUÉniot, David-Alexandre e RE.AL (org.) (200o), DOC.LAB, Uma publicação lesível, n.o o. Lisboa, RE.AL.

LAGEIRA, Jacinto (2013), «João Fiadeiro, repli dans le noir», in Regard oblique: Essais sur la perception, Bélgica, La Lettre Volée.

LEPECKI, André (2017), Exaurir a dança, performance e a política do movimento, São Paulo, Annablume [2006].

- (2014), Seminário «O descomunal, o incomum, o desconforme, o díspar: para uma arte do contrafluxo», in Em reunião, das reuniões como práticas performativas / Das práticas performativas como reuniões, Lisboa, baldio/Teatro Maria Matos.

MIRANDA, José Bragança de (2006), «Queda sem fim», in Queda sem fim, seguido de «Descida ao Maelström», de Edgar Allan Poe, Lisboa, Nova Vega.

RANCIÈ RE, Jacques (2010b), Estética e política, a partilha do sensível, Porto, Dafne Editora, [20oo].

SIMONDON, Gilbert (2007), L'individuation psychique et collective, Aubier, [1958].

\section{OFICINAS}

2014 - Workshop com João Fiadeiro Composição em Tempo Real aplicada à dramaturgia, RE.AL, Lisboa.

2013-2015 - Grupo de Tradução proposto para o baldio - estudos de performance, trabalhando e apresentando palavras como «atenção», «não», «escape» ou «complicar» (o Grupo de Tradução foi um dos pontos de encontro entre o AND_Lab e o baldio e desenvolvia uma visão alargada daquilo que pode significar traduzir, incluindo a tradução entre meios e o jogo da performatividade das palavras), Atelier Real, Lisboa.

2011 - Projecto AND Research, oficina de trabalho intensivo, de dois meses, para exploração de pesquisas individuais e de grupo com apresentação pública final, Atelier Real, Lisboa.

2011 - Projecto AND Extensive, oficina de trabalho intensivo de duas semanas para desenvolvimento das ferramentas do $A N D_{-} L a b$, Atelier Real, Lisboa.

2007/2008 - Aulas semanais de Composição em Tempo Real com João Fiadeiro e Cláudia Dias.

2006 - Workshop de Composição em Tempo Real com a Cia RE.AL/João Fiadeiro.

2006 - Aulas semanais de composição em tempo real com João Fiadeiro (com discussão em torno do método).

2005 - Workshop de Composição em Tempo Real com João Fiadeiro, RE.AL, Lisboa.

1997-1999 - Lab7, Lab8 e Lab9, RE.AL, Lisboa, Centro Cultural de Belém e Lugar Comum/Fábrica da Pólvora.

\section{SÍLVIA PINTO COELHO}

É coreógrafa, investigadora e professora auxiliar convidada da Faculdade de Ciências Sociais e Humanas da Universidade Nova de Lisboa. Inicia o seu pós-doutoramento com bolsa da Fundação para a Ciência e Tecnologia em 2019. É doutorada e mestre em Ciências da Comunicação, licenciada em Antropologia, bacharel em Dança. Entre 1996 e 2019, coreografou e participou em processos coreográficos e pedagógicos e em filmes. 